\title{
PH90
}

\section{Tejiendo La Calle, arquitectura efímera hecha a mano}

Los vecinos de Valverde de La Vera, un pueblo de Cáceres situado a los pies de la sierra de Gredos, desde el año 2013 pasan los meses previos al verano Tejiendo La Calle. Se trata de un proyecto abierto a la participación ciudadana que consiste en la elaboración de parasoles mediante la técnica de ganchillo $\mathrm{XXL}$, utilizando bolsas de plástico recicladas, que luego son instalados de manera temporal en las calles de Valverde durante los meses de calor. A través de esta práctica artística colaborativa, que durante julio y agosto de 2016 ha celebrado su cuarta edición consecutiva, se interviene en el espacio público, se toma conciencia del entorno y se fortalecen los lazos afectivos de la comunidad. Casi medio centenar de valverdanos de todas las edades participan diseñando y tejiendo los toldos y experiementando cada año con nuevas técnicas.

Marina Fernández Ramos | impulsora del proyecto Tejiendo La Calle

URL de la contribución <www.iaph.es/revistaph/index.php/revistaph/article/view/3829>

A través de prácticas colaborativas que intervienen en el espacio público es posible tomar conciencia del entorno que habitamos, construir patrimonio social, cultural, y fortalecer lazos afectivos de una comunidad. Prácticas artísticas colaborativas, acciones de Craftivismo o proyectos de Placemaking posibilitan la generación de espacio social, de un entorno más conectado con las necesidades de sus habitantes.

Intervenir las calles con elementos autoproducidos es un ejercicio de participación con el entorno, una manifestación de que los propios vecinos podemos transformarlo. Así mismo, es un ejercicio de libertad y tolerancia, de reivindicación de distintos posicionamientos, afectos, y múltiples opciones posibles.

En Valverde de La Vera, pequeño municipio localizado a los pies de la Sierra de Gredos en Cáceres, Extremadura, llevamos desarrollando el proyecto Tejiendo La Calle desde 2013, y está resultando una experiencia muy enriquecedora para el pueblo.

Tejiendo La Calle es un proyecto abierto a la participación que consiste en la elaboración de parasoles mediante técnica de ganchillo XXL que son instalados de manera temporal en las calles de Valverde durante el verano. Desde el arranque del proyecto la implicación de muchas mujeres del pueblo resulta altamente positiva.

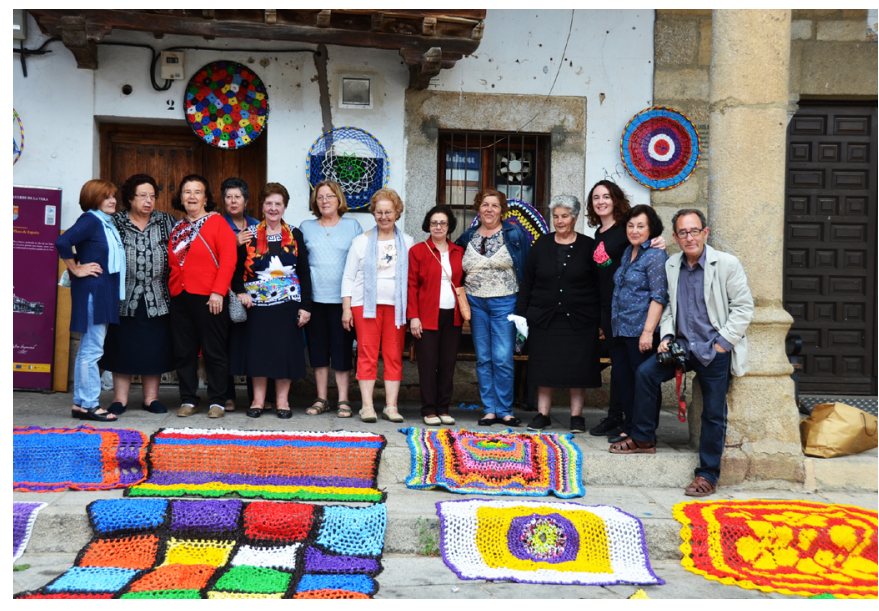

Participantes en la edición de 2016 | foto Luis Ragel

Valverde es conjunto histórico artístico, con un valioso patrimonio de arquitectura tradicional en piedra, adobe y madera, viviendas con patios interiores y calles estrechas con balconadas enfrentadas. La población del municipio es de 529 habitantes censados en 2015, mayormente personas de edad avanzada. Se dan pocos nacimientos, y hay escasas opciones laborales para los jóvenes, por lo que muchos salen del pueblo para formarse y trabajar en otros lugares. En verano, durante la temporada de vacaciones, la población llega a triplicarse.

Se trata de un proyecto que realizamos en equipo. Cada persona se involucra tomando diferentes iniciativas según su voluntad: diseñar y tejer, realizar prototipos de 
piezas para testar cómo funcionan, poner de acuerdo a amigas y vecinas, algunas mujeres han incorporado la actividad en sus entornos (como Candela García, en el Campamento Municipal Infantil), otras personas colaboran en la instalación de las piezas en las calles, así como diferentes tareas colaborativas.

Participamos alrededor de 40 vecinos de todas las edades, en su mayoría mujeres, dos hombres por el momento, y desde la edición de 2014 también hemos contado con la participación de niños y niñas del pueblo. Cada año tratamos de abrir las posibilidades de acción, proponiendo nuevas opciones textiles.

Se activa un conocimiento que pertenece al contexto, adaptándolo a una escala mayor para su integración en el espacio público, los tejidos elaborados cubren las calles del pueblo. La instalación que se realiza ayuda a expresar la propia identidad del lugar y se convierte en soporte de las intenciones y deseos de los participantes en el proyecto. Los motivos o representaciones son los propios de las labores realizadas tradicionalmente en la zona, se trata de dibujos que pertenecen al imaginario colectivo del lugar. Así mismo, las tejedoras realizan sus propios nuevos diseños personales. Se trata de una obra colectiva compuesta por la suma de piezas individuales.

Acoge a los visitantes y colabora en la elaboración de un ambiente con espíritu de celebración. La instalación se realiza en un momento muy significativo, puesto que es cuando regresan los familiares y descendientes que emigraron, y se reciben numerosas visitas. El turismo en el pueblo ha aumentado notablemente. Las piezas funcionan como protectores solares durante el día, mejorando las condiciones de sombra en las calles en verano, y llevan incorporada luz por la noche, mostrando el camino a la plaza, centro principal de encuentro durante las fiestas.

Para la realización de los parasoles utilizamos material plástico. Reutilizamos bolsas de la compra o de basura que transformamos en largas tiras que son después tejidas. Las piezas resultantes son ligeras, impermeables y permiten ser almacenadas ocupando poco espacio. Pueden volver a utilizarse de de año en año. La técnica

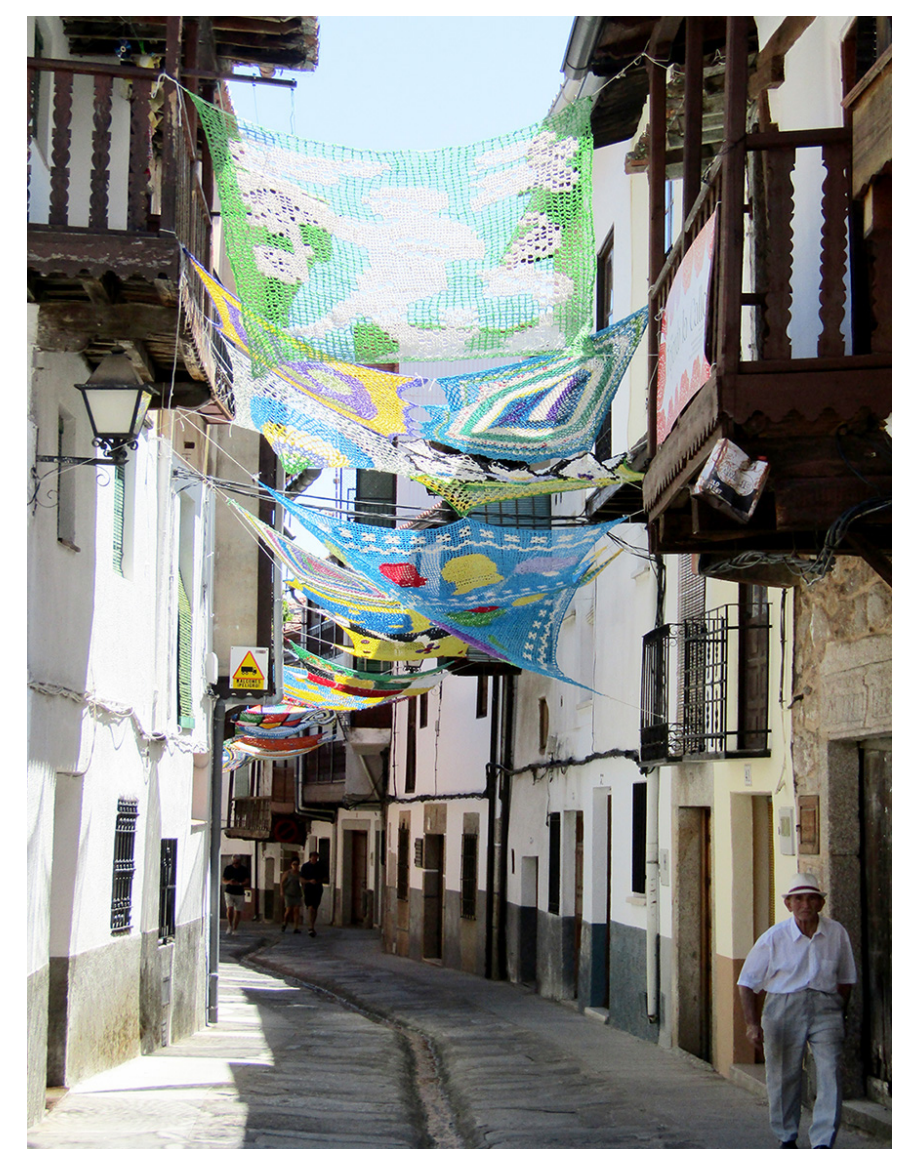

Instalación en las calles de Valverde 2016 | foto Lucía Fernández Ramos

de la que hemos partido es la tradicional de ganchillo, adaptada a una escala mayor, y se ha incorporado el bordado y el tejido en bastidor.

El proyecto consta de diferentes fases durante su desarrollo:

$>$ Una fase de diseño y producción personal de los tejidos, actividad integrada en la dinámica cotidiana de cada participante. Cada persona se organiza de manera independiente o se asocia con amigas o vecinas, y tejen en sus propios hogares.

> Otra fase consistente en una serie de encuentros de producción en la plaza del pueblo, en los que compartimos el trabajo que hemos realizado, las más expertas enseñan a las primerizas, ponemos en común y nos organizamos. Es una oportunidad para relacionarnos de 


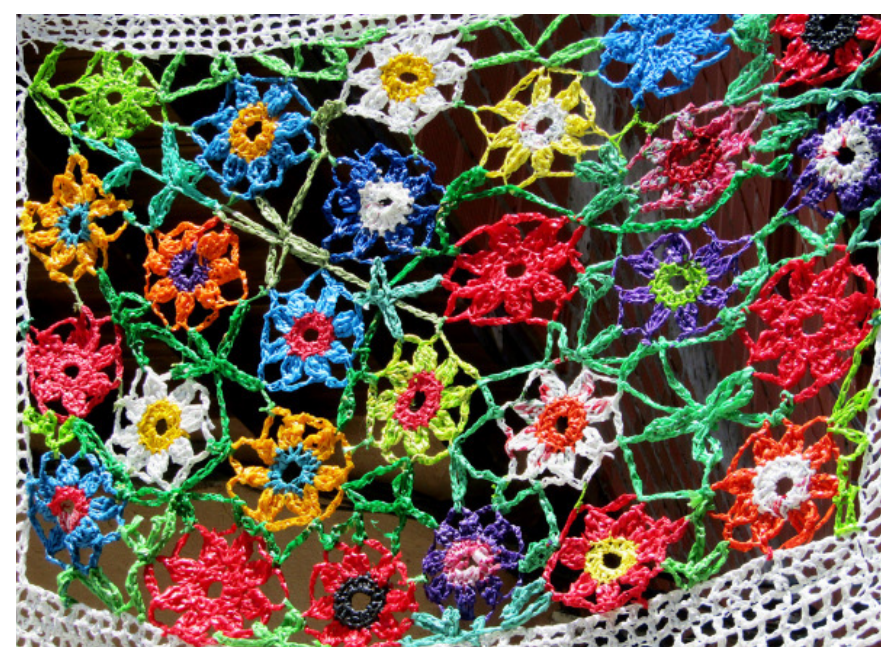

Detalle | foto Lucía Fernández Ramos

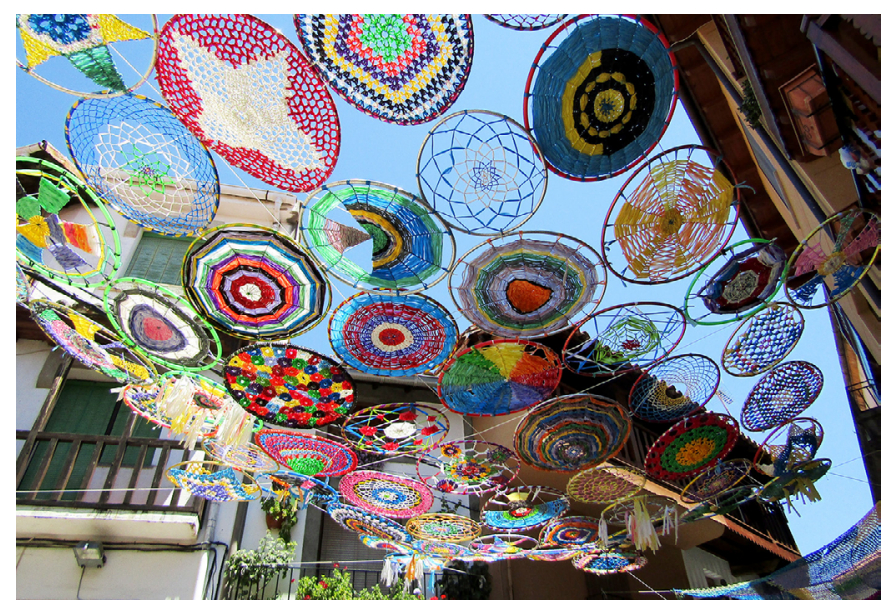

Parasoles Hula Hoop | foto Lucía Fernández Ramos manera diferente a la habitual (construcción de comunidad de afectos).

$>$ Una fase final de muestra del trabajo realizado con la instalación en las calles. Se trata de una acción colectiva de intervención en el espacio público del pueblo. La instalación realizada permanece alrededor de un mes y medio, acompañando la semana cultural y las fiestas de agosto. Durante un tiempo efímero, experimentamos el lugar de manera diferente, descubrimos nuevas maneras de estar en el contexto cotidiano.

Es muy importante reconocer el valor de las labores realizadas tradicionalmente por mujeres para la autogestión y cuidado de sus propios hogares, invisibilizadas o poco valoradas. En Tejiendo La Calle estos elementos domésticos autoproducidos se convierten en una obra colectiva para toda la comunidad. Pasan de formar parte del ámbito doméstico, privado, a manifestarse en el ámbito público, cuidando y arropando las calles del pueblo.

El reconocimiento positivo que está teniendo el proyecto ha tenido un impacto directo en la autoestima de las mujeres tejedoras y de toda la comunidad. Además, a través del Hacer y de la participación en el contexto que se habita se ha generado un nuevo espacio de relación en una comunidad ya establecida, en el que es posible la modificación o generación de nuevos roles de relación entre vecinos. Se fomenta la creatividad, se trabaja la inclusión y la tolerancia, y se construyen nuevas formas de imaginar el entorno que vivimos. 